\title{
Salience and the Disposition Effect: Evidence from the Introduction of 'Cash-Outs' in Betting Markets*
}

\author{
Alasdair Brown ${ }^{\dagger}$ \\ Fuyu Yang $\ddagger$ \\ University of East Anglia \\ University of East Anglia
}

November 23, 2016

\footnotetext{
${ }^{*}$ We would like to thank Paul Pecorino, the Editor, and two anonymous referees for helpful suggestions and comments. We are also grateful to Adam Rivers, Maurizio Fiaschetti, Bob Sugden, and audiences at UEA, the 2016 Royal Economic Society Annual Conference in Sussex, and the Behavioural Finance Group at Queen Mary for earlier feedback. Alasdair Brown acknowledges financial support from the British Academy and the Leverhulme Trust (Ref: SG140097). The research presented in this paper was carried out on the High Performance Computing Cluster supported by the Research and Specialist Computing Support service at the University of East Anglia. The usual disclaimer applies.

${ }^{\dagger}$ Corresponding Author. School of Economics, University of East Anglia, Norwich NR4 7TJ, U.K.. Email: alasdair.brown@uea.ac.uk

${ }^{\ddagger}$ School of Economics, University of East Anglia, Norwich NR4 7TJ, U.K.. Email: fuyu.yang@uea.ac.uk
} 


\begin{abstract}
The disposition effect describes the tendency of investors to sell assets that have increased in value since purchase, and hold those that have not. We analyse the introduction of betting market 'Cash-Outs', which provide a continual update - and therefore increase the salience - of bettors' paper profits/losses on each bet. We find that the introduction of Cash-Out increased the disposition effect in this market, as punters sold their profitable bets with greater frequency than before. We do not, however, find that the disposition effect has any impact on asset prices, either before or after this intervention.
\end{abstract}

JEL Classification: G02, G12, G14

Keywords: disposition effect, salience, prospect theory, betting

\title{
1 Introduction
}

Investors are more likely to sell stocks that have appreciated in value since the purchase date, than stocks which have depreciated in value. This common finding has - since Shefrin and Statman (1985) - been dubbed the 'disposition effect', as investors display a 'general disposition to sell winners too early and hold losers too long? The disposition effect is observed amongst both real-world investors (see Odean, 1998, among many others) and laboratory subjects (Weber and Camerer, 1998). In addition, there is also evidence that a similar reluctance to realize losses is an important factor in the residential property market (Genesove and Mayer, 2001).

A common explanation for this investment (or disinvestment) pattern is prospect theory (Kahneman and Tversky, 1979). The laboratory evidence that underpins prospect theory showed that subjects are risk-taking over potential losses, and risk-averse over potential gains. ${ }^{1}$ Translating this idea to financial markets, this implies that investors sell their good

\footnotetext{
${ }^{1}$ Tversky and Kahneman (1992) developed an extended model - cumulative prospect theory - in which subjects are risk-averse (-seeking) with regards to gains (losses) for high probability bets, and risk-seeking (-averse) with regards to gains (losses) for low probability bets. In the finance literature, Barberis and Huang (2008) use this model to explain the negative returns for stocks with positively skewed returns.
} 
performing stocks in order to avoid risk amongst their gains, and hold their poorly performing stocks in order to retain risk amongst their losses. ${ }^{2}$ Barberis and Xiong (2009) show that prospect theory preferences reliably lead to a disposition effect if utility is realized when stocks are sold, but not if utility is realized annually on the basis of paper profits.

In this paper we investigate whether making certain key information more salient - in this case the profit or loss that a trader can make by unwinding their position - exacerbates the disposition effect. If traders make sell and hold decisions on the basis of where the current price is compared to their purchase price, we might expect that an increase in the saliency of the purchase price, or an increase in the saliency of their potential profits or losses, may increase the tendency to sell winners and hold losers.

We study 6 seasons of soccer betting - from August 2008 to May 2014 - on Betfair, a U.K. betting exchange, to find out. In February 2011, Betfair introduced a new 'CashOut' facility. This involved the introduction of a prominent yellow display, placed centrally in the browser interface, indicating the profit or loss that a bettor could expect to make if they unwound their earlier bet at currently quoted prices. A button accompanied this display which, if pressed, unwound the punter's position. This change to the market design represents a 'natural experiment' on the impact of salience on the disposition effect. Prior to the introduction of Cash-Out, punters would have had to independently recall their previous trading price, and then, on their own, calculate the profit or loss that would result from an exit from their position, and then decide whether or not to trade.

Although we do not have account-level data, we do find that prior to the introduction of Cash-Out there were trading patterns consistent with a pronounced disposition effect in this market. The frequency of sell market orders was $68.1 \%$ higher if a bet was trading, inplay, at a higher price than its pre-match average, compared to if the bet was trading at a lower price than its pre-match average. What is more, the introduction of Cash-Out in February 2011 - which increased the salience of the profits/losses that would be accrued by closing

\footnotetext{
${ }^{2}$ Ben-David and Hirshleifer (2012) argue that the trading pattern is also consistent with biased investor beliefs combined with overconfidence. The idea is that investors are more likely to sell their winners because they believe that their private information is now reflected in the price, yet hold their losing stocks as they are (overconfidently) waiting for the market to come around to their way of thinking. Our tests do not allow us to distinguish between preference-based and belief-based explanations for the disposition effect.
} 
out the position - exacerbated this disposition effect. After this change in market design, punters were a further $4.2 \%$ more likely to sell a bet trading at a profit than a bet trading at a loss. In short, we find that the salience of the profits or losses on the table has a significant impact on the magnitude of the disposition effect.

Recent papers have shown that there is not a jump in the probability of the sale of a stock when profits exceed zero (see Ben-David and Hirshleifer, 2012, and An and Argyle, 2015). Instead, there is a V-shaped trading pattern, with infrequent sales at small profits or losses, but frequent sales at large profits or losses. In particular, investors are highly likely to sell stocks that have reaped large profits. This pattern of trading casts doubt on the prospect theory explanation, as prospect theory would imply a jump in the sale probability, around 0 , as a stock drifts into profit. ${ }^{3}$ We also find a V-shaped trading pattern in our data, with pronounced selling when prices are much higher or lower than their pre-match level. Furthermore, we find that Cash-Out - and the resultant increase in profit/loss salience amplified this trading pattern.

In this paper we also examine whether short-sellers exhibit a disposition effect. With the exception of von Beschwitz and Massa (2015), there has been little evidence on whether short-sellers trade with the same bias. On the exchange, bettors can short or bet against an outcome prior to matches. To examine the disposition effect for short-sellers, we can then compare the frequency of inplay buy orders for instances when the bet is trading below its pre-match price (and is, to the short-seller, a winner), with the frequency of buy orders when the bet is trading above its pre-match price (and is, to the short-seller, a loser). To our surprise, we find trading patterns consistent with a reverse disposition effect for these types of bets. Punters were more likely to buy back the bet if trading at a loss than if it was trading at a gain; in other words, it would appear that they were risk-averse over losses and risk-taking over gains. Having said that, the introduction of Cash-Out induced a more traditional disposition effect, and short-sellers began to unwind their winners with greater frequency when the saliency of their profits and losses increased.

\footnotetext{
${ }^{3}$ The prospect theory explanation for the disposition effect has also come under attack from the theoretical side. Hens and Vlcek (2011) show that the prospect theory preferences necessary to generate the disposition effect would, for experimentally-estimated parameters, fail to lead to buying of stocks in the first place.
} 
This paper contributes to a vast literature on the disposition effect. Part of the academic interest in this behaviour is due to the perception that the disposition effect is harmful to trading performance, and may even have a distortionary effect on asset prices. If traders sell those stocks that have performed well, and hold those that have performed badly, then they are likely to miss out on the momentum that has been found in stock returns (Jegadeesh and Titman, 1993). Furthermore, others argue that the disposition effect in fact causes momentum (and also the post-earnings announcement drift), as selling pressure after a stock price rise prevents prices from fully revealing good news (see Grinblatt and Han, 2005, and Frazzini, 2006). Recently, An (2016) documents that the extreme winners and losers - i.e. those stocks that are sold in a V-shaped trading pattern - go on to earn abnormal returns, suggesting that the $\mathrm{V}$-shaped disposition effect distorts prices. However, momentum can exist independent of the disposition effect. Indeed, Birru (2015) shows that the magnitude of the disposition effect is small relative to stock price momentum, and that momentum is still observed for stocks where there is little or no disposition effect trading.

Our setting allows us to evaluate the effect of the disposition effect on mispricing. Part of the problem with identifying momentum or reversal in stock returns is the sensitivity of the calculations to the horizon chosen. Momentum may be observed over certain horizons (e.g. 1 year), but a reverse contrarian strategy may perform better over a different, perhaps longer, horizon (De Bondt and Thaler, 1985, and Fama, 1998). In our setting, the horizon is less important, as we observe fundamentals at the end of each match. If the disposition effect leads to poor trading performance, or indeed causes mispricing, we may expect to see bets that are trading above their pre-match level win more often than their price implies. This is because bettors with the disposition effect will sell off their winning positions too early, and too cheaply. However, in our data set of 2,143 soccer matches, we find no evidence that the disposition effect has a distortionary impact on prices. This result applies both to the standard disposition effect, and the V-shaped refinement. Furthermore, even when the disposition effect is amplified by the increase in salience created by the introduction of Cash-Out, there is still no significant effect on asset prices.

However, the obvious question of external validity still hangs over our results. To what extent can results in betting markets be extrapolated to larger scale financial markets, where 
experience and incentives may lessen the impact of paper profit salience? It is true that the disposition effect is less pronounced amongst professional traders (Da Costa et al., 2013). However, there is evidence to suggest that behaviour in betting markets is not totally removed from financial market behaviour. For example, Kuo et al. (2015) argue that investment in stocks and lotteries are to some extent substitutes, as volume in lottery-like stocks decreases when there is a jackpot roll-over. In addition, Kumar (2009) shows that state lotteries and lottery-like stocks attract very similar individuals. And the depth of trading on Betfair, and therefore the disciplining effects of this market, may be greater than some think. For example, 8.8 billion GBP is wagered during the 2,143 matches we study.

Many authors have used betting markets in order to study market efficiency (and related questions), including Ali (1977), Snowberg and Wolfers (2010) and Brown and Yang (2014). To our knowledge, the only paper to use betting/prediction markets to study the disposition effect is Hartzmark and Solomon (2012), who looked at National Football League (NFL) betting on Tradesports. One possible reason why the literature has not pursued this angle much before, is that, historically, bets were typically held until maturity (i.e. until the end of the sporting event). The development of inplay betting - studied both by ourselves and Hartzmark and Solomon - allows bettors to trade in and out of positions in a way not seen in the past, and - because fundamentals are revealed for betting assets - allows for a consideration of the impact of the disposition effect on asset prices. Hartzmark and Solomon find, in contrast to us, that the disposition effect amongst bettors has a distortionary impact on asset prices, as 'prices are too low when teams are ahead and too high when teams are behind'. We not only report different results to Hartzmark and Solomon, but also explore the effect of salience on the magnitude of the disposition effect, and any resultant impact of this salience on asset prices.

In attempting to tie the magnitude of the disposition effect to the salience of a trader's paper profits, our work is perhaps closest in spirit and aims to Frydman and Rangel (2014). Frydman and Rangel conducted a lab experiment to examine whether alterations to the salience of the subject's purchase price had an effect on the magnitude of the disposition effect. They found, as we do, that increased salience leads to a more pronounced disposition effect. In addition, they found that doing away with information on a subject's purchase 
price does not eliminate the disposition effect. (We find the same result, as the disposition effect seems to have been present before Cash-Out). While we trail that experimental paper in terms of internal validity (though we explore a range of confounding explanations for our results in Section 3), we exploit the greater external validity of our natural setting. It is important to consider the disposition effect in a natural environment, as there is evidence that anomalous behaviour declines with experience (e.g. Loomes et al, 2003, List, 2003), and that professionals - of which there may be some in this betting market - are less likely to exhibit the disposition effect than non-professionals (see Dhar and Zhu, 2006, and Da Costa et al., 2013). In addition to replicating Frydman and Rangel's results outside the lab, we also explore the disposition effect amongst short-sellers (and how these short-sellers respond to the salience treatment), and, more generally, test whether the disposition effect has an impact on asset prices.

Our paper also illustrates how a supposed behavioural bias - namely the disposition effect - can interact with limited attention in asset markets. (Evidence of the effect of limited attention on asset prices can be found in DellaVigna and Pollet (2009) and Hirshleifer et al. (2009) for financial markets, and Brown $(2014,2015)$ and Brown and Yang (2016) for betting markets). One of the reasons why salience may have an impact on the magnitude of the disposition effect is because investors/bettors have limited capacity to receive, process, and act upon information. The introduction of Cash-Out circumvents some of these limitations: bettors no longer have to manually evaluate the current prices of bets relative to the price at which they bought. The value of their position is updated and displayed continuously, and can be unwound at the press of a button. Our evidence suggests that the greater salience created by Cash-Out - which also mitigated bettors' limited attention - led to an even more pronounced tendency to close winning positions and hold losing positions.

This brings us to the implications of our results. There is, it would appear, potential to reduce the extent of the disposition effect in asset markets by altering the salience of an investor's current position. While Cash-Out increased this salience, attempts could be made to reduce this salience, or shroud such information, if a market designer or regulator so wished. It should be said, however, that such an approach is unlikely to eliminate the disposition effect, as the effect arose in our setting even without any running information 
on a bettor's position. More importantly, our results also suggest that the disposition effect neither harms the trader who exhibits it (through poor performance), nor has an impact on aggregate market prices. Therefore, unless there are pronounced tax reasons for not exhibiting the disposition effect (realized losses can often be used to reduce tax liabilities from profits elsewhere in the portfolio), there is arguably little reason to interfere with its prevalence.

The rest of this paper is structured as follows. In Section 2 we describe the Betfair betting exchange, the specifics of Cash-Out, and our data. Section 3 contains the analysis. Section 4 concludes.

\section{Data}

The setting for our study is Betfair, the world's largest betting exchange, founded in the U.K. in the year 2000. Betting exchanges operate in a different fashion to traditional bookmakers, in that they take no positions themselves, but instead facilitate the trading of bets by others. ${ }^{4}$ In this sense, they operate in a very similar way to financial exchanges. Bettors can provide quotes (using limit orders), or execute at quotes provided by other bettors (using market orders). The exchange format also allows punters to bet on outcomes (via back bets), or bet against outcomes (via lay bets). Betting on an outcome is equivalent to buying a betting asset, and betting against an outcome is equivalent to (short-)selling a betting asset. Trading on these exchanges takes place in the days and hours before a match (pre-match), and during the match itself (inplay).

In February 2011, Betfair launched Cash-Out on the exchange. ${ }^{5}$ This provided bettors with a continual update of the profit, or loss, that they would make if they unwound their bet at that moment. The calculation is based on current quotes provided by other bettors. Therefore, if a punter had placed a bet on a team to win before the game (i.e. bought the betting asset), and the team was now leading 3-0, for example, during the match, Cash-Out would indicate that a potential profit was available if they were to now lay (i.e. sell) the

\footnotetext{
${ }^{4}$ In recent years, Betfair have also entered the bookmaker market, via their 'Sportsbook', but this market is separate from the exchange that we study.

${ }^{5}$ Similar Cash-Out features have since been aped by almost all of the major bookmakers.
} 
bet. If, on the other hand, the team was losing 3-0, and the price of this bet had declined since the pre-match period, Cash-Out would reveal the magnitude of the loss that they could immediately incur in order to close the position. Prior to Cash-Out, bettors could of course close out their positions, but there was no indication on the exchange of the profit or loss that they would make, or of the precise volume that they would need to trade in order to fully hedge their earlier bet.

To get an idea of the nature of Cash-Out, see Figure 1. This is a screenshot of the Betfair exchange for a match between Swansea City and Manchester City on the 17th May 2015. Prior to the match, a 5 GBP bet on Swansea City to win was placed at odds of 4.9. (Odds on Betfair include the stake, and therefore such a bet returns 3.9 GBP for every 1 GBP staked). These odds imply a win probability (or price) - assuming prices are set so as to break even of $1 / 4.9=0.204$. If this bet is held until the end of the match, and Swansea win, 19.50 GBP will be returned in addition to the 5 GBP stake. If Swansea do not win, the stake is lost. The bettor, of course, has the option to close out the position before the end of the match. The Cash-Out feature - displayed prominently in the centre of the screen near the top - indicates that the bettor can sell their bet at a current profit of 8 pence. This is because Swansea City's prospects have marginally improved, and the lay (sell) odds are now 4.8. (The bettor would actually have to execute part of their bet at odds of 4.9, as only 2 GBP is quoted at 4.8). Odds of 4.8 imply a win probability (or price) of 0.208 . Prior to the introduction of Cash-Out, the appearance of the exchange was exactly the same, but the Cash-Out bar and the information on the bettor's current paper profits/losses - was absent. ${ }^{6}$

To study the impact of the increased salience created by the introduction of Cash-Out, we collected data from Fracoft, a third-party provider of Betfair limit order book data. This data include second-by-second observations of the best back (buy) and lay (sell) quotes, and associated volumes with each quote. In addition, this data include the last matched price and total matched volume, measured each second. We obtained the full Fracsoft database for the English Premier League seasons 2008/9 through 2013/14. This includes 2,143 matches out of a possible total of 2,280 (there are 380 matches per season). The remaining matches

\footnotetext{
${ }^{6}$ Since its introduction, bettors are able to opt-out of Cash-Out - and have it removed from their browser display - but its presence is the default option.
} 
are missing from the Fracsoft database. Within the 2,143 matches we do have, there are bets on 6,318 different outcomes out of a possible 6,429 (there are 3 potential outcomes - win, lose, draw - per match). For all of these matches, we have data for the pre-match period and inplay. This yields more than 130 million observations.

Unlike the majority of studies of the disposition effect, we do not have trader identification codes. However, the specifics of soccer betting allow us to, in our view, circumvent this problem. As prices display very little volatility prior to matches, we can estimate - with some precision - the price that a bettor would have obtained if they had bet prior to a match (we take the average quoted price). Then, we can analyse the frequency of buy and sell orders during the match, dependent on where the inplay price is relative to this pre-match average. If sell frequencies are higher when the bet is priced higher than the pre-match price - compared to when bets are priced lower than the pre-match price - this is indicative of the disposition effect.

In using market-wide data rather than individual trader transactions, we follow a similar approach to Kaustia (2004). Kaustia analysed trading volume in the weeks following an initial public offering (IPO). The price at which an initial investor bought in is defined in the IPO prospectus. Therefore, if volume is higher for stocks where the price has taken off since the IPO - compared to stocks where the price has plummeted since the IPO - this is consistent with the disposition effect (i.e. IPO investors are selling their winners, and holding their losers).

The IPO setting used by Kaustia does have one advantage over our setting. In the stock market, the average investor has a long position, as the firm has issued new shares. A betting exchange is more similar to a futures market, where the aggregate long position is always equal to the aggregate short position. Unfortunately, this means that we may be confounding many types of trading behaviour with the disposition effect. For example, suppose that we observe an inplay sell (market) order when the price is above the pre-match level. This could be driven by:

(a) a trader closing their winning long bet via a market order (i.e. a disposition effect trade) 
(b) a trader closing their losing short bet via a limit order (i.e. a reverse disposition effect trade)

(c) a trader with a winning long bet opening up a larger position via a limit order (this type of extra buying of winning stocks was observed in Ben-David and Hirshleifer, 2012)

(d) a trader with a losing short bet opening up a larger position via a market order

(e) a trader, who didn't bet pre-match, opening up a new short position with a market order

(f) a trader, who didn't bet pre-match, opening up a new long position with a limit order

Of course, for any buyer (long trader) there must be a seller (short trader). This means that any occurrence of $(\mathrm{a}),(\mathrm{d})$ or $(\mathrm{e})$ - i.e. a bet against a team - must be accompanied by one of (b), (c) or (f) taking a long position. Importantly, however, Cash-Out only works for option (a). Cash-Out only applies to the closing of positions via a market order. It is not possible to use Cash-Out in any other way. Therefore, when we observe an increase in the frequency of sell market orders - when the price is above its pre-match level - after the introduction of Cash-Out, it is likely that this is driven by an increase in the frequency of (a), disposition effect trades, rather than (d) or (e), non disposition effect trades. In other words, while we cannot precisely estimate the magnitude of the disposition effect prior to Cash-Out, we can examine whether Cash-Out increased or decreased its prevalence.

For our upcoming analysis, we calculate the price of each bet, each second. We measure this in implied probability terms. For example, if the best back (buy) odds for a bet are 2, and the best lay (sell) odds are 2.02, then the implied win probability (as inferred from the midpoint of the spread) is $(1 / 2+1 / 2.02) / 2=0.498$. Summary statistics for the price can be found in the top panel of Table 1. We break the sample down into the pre-match period, and the inplay period. As should be expected for bets on matches with three possible outcomes, the average price for bets, both pre-match and inplay, is approximately 0.33 . There is greater variation in the price during matches, with some bets priced toward 1 (as the outcome nears realization), and others nearing 0 (as the outcome becomes an impossibility). Note that the 
standard deviation in price in the pre-match period is not calculated within each bet - in which case there would be very little variation - but is instead calculated across all bets.

Our second area of interest is the direction of orders, i.e. did the market order trader buy the bet, or sell the bet? Note again that Cash-Outs only operate by placing market orders. For the purposes of classifying orders we use the Lee and Ready (1991) algorithm, which works as follows. Firstly, if the total matched volume for a bet is higher at time $t$ than time $t-1$, then an order has been placed. Secondly, if the last matched price at time $t$ is closer to the best back odds at time $t-1$, then it was a buy order, and if it was closer to the best lay odds at time $t-1$, it was a sell order. Applying this algorithm to our data-set, we are able to classify $97.5 \%$ of inplay orders; the remaining $2.5 \%$ were executed at the precise midpoint of the spread and could not be classified.

We present summary statistics on buy and sell order indicator variables in the bottom panel of Table 1. We will be examining the extent to which punters sell their profitable bets and hold on to their losing bets. We therefore concentrate on the inplay period for orders, as the arrival of match information pushes prices away from their pre-match levels, thus generating the variation we require for our tests. Looking at Table 1, we can see that buy orders occur in $14.5 \%$ of seconds sampled, and sell orders occur in $12.2 \%$ of seconds sampled. (The nature of the data, and the Lee and Ready algorithm, means we have to assume that only one type of order can take place in any one second).

To give an indication of the initial results in the next section, we produce Figures 2 and 3. In Figure 2, we plot the frequency of sell (lay) market orders as a function of the difference between the current inplay price (the price bettors sell at), and the pre-inplay average price (our estimate of the price that bettors bought in). This difference is rounded to 1 decimal place, to ensure we have sufficiently large buckets of observations. We also truncate the plot at differences of -0.75 and 0.75 , as there are fewer observations when the price has moved a long way from its pre-match level. We find that there is a pronounced V-shape to the plot, indicating that bettors are more likely to unwind their position when their profits and losses are large, rather than small. A similar V-shape pattern, with the bottom of the V located at profits of 0, can be found in Ben-David and Hirshleifer's (2012) analysis of accounts with a large discount brokerage. This similarity is comforting for two reasons. Firstly, it suggests 
that betting market behaviour is similar enough to financial market behaviour for our study to yield informative conclusions about behaviour in financial markets. Secondly, it suggests that even though we do not have individual trader records, our approximation of the price at which bettors originally transacted (i.e. the pre-match price) is accurate enough to generate similar behaviour to that observed with individual trader records. Also in common with Ben-David and Hirshleifer (2012), we find that the line is steeper when dealing with profits (on the right-hand-side). This indicates that bettors are more likely to sell their winning bets than their losing bets. This pattern is consistent with the disposition effect.

In Figure 3, we repeat this analysis for buy (back) market orders. As was the case with sell orders, bettors are more likely to unwind their position if their profits or losses are large (hence the V-shape). However, it is not clear that short-sellers have a greater propensity to unwind their winners or their losers. If short-sellers were to unwind their winners with greater frequency, we would observe a steeper line on the left-hand-side, as this is the region where the bet has fallen in value and is, to the short-seller, a winner. That does not appear to be the case. In the next section, we will test for the disposition effect - amongst both long bettors and short-sellers - more formally.

\section{Analysis}

We begin, in the left panel of Table 2, by analysing whether there is evidence consistent with a disposition effect in this market. We regress an indicator variable - equalling 1 if a sell (lay) market order is observed in that second - on an indicator variable equalling 1 if the bet is quoted at a higher price than its pre-match average. Only inplay orders are considered, and estimation is by OLS, with heteroskedasticity-consistent standard errors clustered at the bet-level. ${ }^{7}$ All data for the six seasons - both before and after the introduction of Cash-Out

\footnotetext{
${ }^{7}$ We estimate a linear probability model by OLS, because there are computational difficulties in estimating a logit/probit with more than 39 million observations. The main problem with the linear probability model is that the estimates are biased if a substantial proportion of the predicted values lie outside of the unit interval (Horrace and Oaxaca, 2006). However, within all of the regressions we present in this paper, there is not a single predicted value outside of the unit interval. This should lessen any issues with bias in our OLS estimates.
} 
- are included in this regression. If the coefficient associated with the main regressor is positive, this means that bettors are more likely to sell bets if they are currently trading at a profit than if they are currently trading at a loss. We find that the coefficient is indeed positive, suggesting that there is a disposition effect in this market. Sell orders occur in $9.9 \%$ of seconds when the bet is trading at a loss, but occur in $16.9 \%$ of seconds if the bet is trading at a profit.

We next turn to the short-sellers' disposition effect. If a bettor has (short-)sold a bet prior to a match, this bet is profitable if subsequently trading inplay at below the pre-match price, and unprofitable if trading above the pre-match price. Therefore, if the disposition effect is to be found amongst short-sellers, we would expect to observe more buy orders, inplay, when the bet is trading below its pre-match level. With this in mind, in the right panel of Table 2, we regress an indicator variable equalling 1 if a buy (back) market order was observed in that second, on an indicator variable equalling 1 if the bet was trading below its pre-match average. We find no significant effect; it appears that short-sellers are equally likely to unwind (or buyback) their winners as their losers.

As mentioned in the Introduction, a recent refinement to the disposition effect is the notable V-shape in selling patterns (Ben-David and Hirshleifer, 2012, An and Argyle, 2015). Investors are more likely to sell extreme winners and losers, particularly extreme winners. A similar pattern seems to be present in our data, based on Figures 2 and 3. To more formally test for such a pattern, in Table 3 we present additional regression results. In the top panel, an indicator variable equalling 1 if a lay (sell) market order was placed, is regressed on an indicator variable equalling 1 if the bet was, at the time, quoted at a higher price (implied win probability) than its pre-match average, the absolute difference between the pre-match price and the current price, and an interaction between the two variables. The absolute difference term captures the $\mathrm{V}$-shape, and the interaction term allows us to assess whether the $\mathrm{V}$ is steeper amongst gains. Our results confirm that there is indeed a V-shaped selling pattern, and that the disposition effect is driven in part, but not completely (the first indicator is still significant), by a more pronounced selling response to extreme winners compared to extreme losers.

In the bottom panel of Table 3, we repeat the exercise for short-sellers and buy(-back) 
market orders. Here, the results are more complicated. When we allow for a V-shaped buying pattern (which is present), we find a regular disposition effect (winners are sold more often than losers), but the $\mathrm{V}$ is steeper amongst losses than gains. In other words, once you account for short-sellers' general propensity to unwind winning bets, extreme losing bets are more likely to be unwound than extreme winning bets.

Our main analysis focuses on the effect of the market design change. In Table 4, we repeat the analysis of Table 2, but this time add two further regressors. In the left panel, the first additional regressor is an indicator variable, labelled 'Treatment', equalling 1 if the match in question was after the introduction of Cash-Out in February 2011. The treatment indicator captures any greater frequency of sell orders that coincided with the introduction of Cash-Out. As outlined in Section 2, Cash-Out not only increased the salience of a better's paper profits and losses, but also made it much easier to close out a position (by calculating the necessary volume and executing the trade). We may therefore expect the frequency of sell orders - even for those making a loss - to increase after the introduction of Cash-Out. The second regressor in our new specification is an interaction between an earlier indicator equalling 1 if the bet was priced above its pre-match average - and the treatment indicator. The interaction term is crucial, as it captures any difference in the frequency of selling off winners, as opposed to selling off losers, after the introduction of the new facility. We find that the introduction of Cash-Out significantly increased the frequency of selling off winners relative to the frequency of selling off losers. This suggests that by making paper profits/losses more or less salient, a market designer can affect the prevalence of the disposition effect.

To illustrate these results, we produce Figure 4. This is a re-production of Figure 2, but this time the sample is broken down into the period prior to Cash-Out ('Untreated'), and the period after the introduction of Cash-Out ('Treated'). As backed-up by our results in Table 4, we find that the frequency of selling losers increased after Cash-Out (see the left-hand-side), but the frequency of selling winners increased to a greater extent (see the right-hand-side). This indicates that the greater salience created by Cash-Out led to an increase in the disposition effect.

In Table 4, we also analyse the effect of Cash-Out on the short-sellers' disposition effect. We regress an indicator variable - equalling 1 if a buy order was observed in that second 
- on an indicator variable equalling 1 if the bet was priced below its pre-match average, an indicator for the treatment (i.e. post Cash-Out), and an interaction between the two aforementioned indicators. Interestingly, our results imply that there was a slight reverse disposition effect prior to the introduction of Cash-Out. Punters were $0.7 \%$ more likely to sell a losing bet than a winning bet. (For short-sellers this means a greater tendency to buy back a bet that has since increased in value). However, as indicated by the interaction term, Cash-Out increased the propensity for short-sellers to unwind their winners (those that have fallen in value), relative to their losers (those that have increased in value), and led as we saw in Table 2 - to what appears to be no net disposition effect. In others word, while the increased salience of a bettor's position increased the tendency to unwind winners, the short-sellers in our market seem to have begun with a slight tendency to unwind losers. One interpretation of this result is that short-sellers are more likely to be sophisticated and experienced traders - as short-selling in betting markets is a recent option for everyone aside from bookmakers - and therefore exhibit less of a disposition effect. The disposition effect was less pronounced amongst experienced/sophisticated traders in Dhar and Zhu's (2006) study of brokerage house investors, and in Da Costa et al.'s (2013) analysis of student and professional investors in the lab. Having said that, if that were the reason behind our results, our 'sophisticated' traders respond in a similar way to the salience treatment as our supposed less sophisticated traders.

We also illustrate these results in Figure 5. Once again, the sample is broken down into the pre-Cash-Out period ('Untreated), and the period after the introduction of CashOut ('Treated'). From this plot there is little to suggest that Cash-Out led to a greater tendency for short-sellers to unwind losers (on the right-hand-side), even though there was some evidence of this in the regression results. In both the regressions and the graph, however, there is evidence that Cash-Out led to a greater tendency for short-sellers to unwind their winning positions (on the left-hand-side). In other words, it appears that a disposition effect was induced, amongst short-sellers, after the salience of their paper profits and losses was increased.

Our next test is to establish the robustness of our results related to Cash-Out. Cash-Out was introduced midway through the third season in our data-set (2010/11). It is possible, 
therefore, that part of our results are driven by seasonality in betting patterns; we have more late season matches after the introduction of Cash-Out than before. One way around this potential issue is to exclude matches in season 2010/11 altogether. This is what we do in Table 5 of our analysis. The analysis in Table 4 is repeated, but this time the 'treatment' period includes season 2011/12 through to 2013/14, and the control period is seasons 2008/9 and 2009/10. Our results are very similar with this slice of the data. Again, there is evidence of a strong disposition effect, made stronger by the increase in salience created by Cash-Out. In addition, there is evidence of a slight negative disposition effect amongst short-sellers, which is eradicated by the introduction of Cash-Out.

We now turn to our second robustness check. One concern with our analysis, thus far, is that we may be confounding the effect of the introduction of Cash-Out with any drift, over time, in betting patterns and behaviour on the exchange. One way around this is to specify a placebo intervention, which occurs after a certain date, but is unrelated to the introduction of Cash-Out. The safest way to carry out such an exercise is to select time periods before the introduction of Cash-Out, as there may be drifts in the use of this facility over time. With this in mind, we concentrate our analysis on seasons 2008/9 and 2009/10. Both seasons occurred before the introduction of Cash-Out. We then specify any match taking place in 2009/10 as our placebo treatment. Therefore, if we are simply picking up drifts in betting behaviour over time, we might expect our placebo treatment to be a significant factor in the magnitude of the disposition effect. In Table 6, we present our results. As expected, we find that there was no significant impact of the placebo treatment on the magnitude of the disposition effect (again captured by the interaction terms in the two regressions). This applies both to the standard disposition effect (on the left-hand side), and the short-sellers' disposition effect (on the right-hand side). This increases our confidence that the changes in the disposition effect that we observed in earlier analyses are indeed due to the increased salience created by Cash-Out.

One other way to limit concerns over changing bettor behaviour over time is to consider the magnitude of the disposition effect very narrowly around the introduction of 'CashOut'. For example, we could exclude all data outside the 2010/11 season, and see whether the disposition effect increased in magnitude at precisely the introduction of Cash-Out in 
February 2011. However, there is anecdotal evidence from internet forums around the time (see betangel.com and community.betfair.com, for example) of significant teething problems with the introduction of Cash-Out. Some bettors complain that their Cash-Out bets will not execute, or execute at prices worse than the best quoted in the book at the time. To avoid this issue, we focus on a much longer time-frame when these teething issues are likely to have been ironed out.

In Table 7 we allow the introduction of Cash-Out to have an effect on the $\mathrm{V}$-shaped selling schedule. We regress an indicator variable equalling 1 if a sell order is observed, on an indicator variable equalling 1 if the bet is priced above its pre-match level, the absolute difference between the pre-match and current price, the treatment indicator (for post CashOut), and interactions between these three variables. We are interested in two interactions in particular. 'Above Pre-Match Price*Treatment', which captures the effect of Cash-Out on the disposition effect, and 'Above Pre-Match Price*Treatment*Abs. Diff. in Price', which captures any effect of Cash-Out on the steepening of the $\mathrm{V}$ amongst gains. As the first of these interactions is not significant, but the second is, this suggests that Cash-Out exacerbated the disposition effect mostly by increasing the propensity to sell extreme winners, not simply the propensity to sell any winners. Based on the results in the bottom panel, short-sellers also unwind their extreme winners with greater frequency after Cash-Out.

In our next piece of analysis, we estimate the effect of the disposition effect - both before and after the introduction of Cash-Out - on asset prices. As mentioned in the Introduction, there is a perception in the literature that the disposition effect slows the impounding of information into prices, as investors are too quick to sell their stocks after a bout of good news, and this selling pressure subsequently leads to momentum in stock returns (Grinblatt and Han, 2005, and Frazzini, 2006). As also mentioned in the introduction, our setting is ideal for evaluating such a proposition. At the end of each match we observe each asset's fundamental value. Therefore, if the disposition effect impacts upon asset prices, we might expect bets to win more often than their price implies - when trading above their pre-match level (i.e. purchase price) - as punters with the disposition effect sell their good performing bets too quickly and too cheaply. On the downside, however, we do not observe whether or not traders are actually closing out their positions and taking gains. We rely on the 
assumption that if a bet is trading above its pre-match price then such behaviour is more likely. In other words, while we have a clean measure of our upcoming dependent variable (asset fundamentals/mispricing), we do not have such a precise measure of our upcoming independent variable (the magnitude/prevalence of the disposition effect).

In Table 8, we begin by examining whether the disposition effect, irrespective of Cash-Out, has an effect on asset prices. We regress an indicator variable - equalling 1 if the outcome occurred (the bet won) - on the price of the bet, and an indicator variable equalling 1 if the bet is currently priced at above its pre-match average. The model fits the data quite well, as the coefficient associated with the price (implied win probability) is insignificantly different from 1. Although the coefficient associated with the indicator variable is positive, there is no statistical significance to its effect. In other words, there is little to suggest that the disposition effect has an impact on asset prices. It is possible, however, that once the salience of bettors' paper profits/losses increases (via Cash-Out), and a more pronounced disposition effect takes hold, then there is an impact on asset prices. With this in mind, in the second regression we add an indicator for the treatment period (after the introduction of Cash-Out), and an interaction between the above pre-match price indicator, and the treatment indicator. This makes little difference to our results. Even when the salience of bettors' paper profits and losses is increased, the amplified disposition effect has no significant impact on asset prices.

In the literature on the disposition effect and stock price momentum, it is common to examine the return predictability that stems from the average investor's capital gains, whilst controlling for past returns (see Grinblatt and Han, 2005). This allows the researcher to see which part of momentum is due to the disposition effect, and which part is independent. With this in mind, we ran a series of additional regressions controlling for past returns over varying horizons. While we cannot control for returns specifically since the pre-match period (as this would be co-linear with our original regressor), we can control for returns over the last 1, 5, 10 or even 60 minutes (for later phases during matches). For space reasons the results of these regressions are not displayed, but in none of these specifications did we find that past returns predicted mispricing. In this sense, our results provide an interesting counterpart to those of Birru (2015). Birru found that stock price momentum (mispricing) was present for 
stocks with little or no disposition effect trading. We find no mispricing in an environment where the disposition effect seems to be prevalent. Both pieces of evidence point to a weak link between the disposition effect and asset mispricing.

However, our initial tests on the disposition effect and asset prices may be too coarse to detect any effect. Perhaps by accounting for the observed V-shaped selling schedule amongst bettors, we may observe a distortionary effect on prices. In Table 9, therefore, we regress an indicator variable - equalling 1 if the outcome occurred (the bet won) - on the price of the bet, an indicator variable equalling 1 if the bet is currently priced above its pre-match average, the absolute difference between the pre-match and current price, and an interaction between the two variables. If the $\mathrm{V}$-shaped disposition effect has an impact on prices, we would expect bets trading at a very large gain to win more often than current prices imply. Based on the coefficient associated with the interaction term, however, this is not the case. Even when we add the treatment (post Cash-Out) indicator - and acknowledge that CashOut amplified the selling pressure amongst large gains - and all of the necessary interactions, we find no significant impact on asset prices.

To sum up, we have seen little evidence that the disposition effect had a distortionary impact on asset prices, either before or after the introduction of Cash-Out. The only way, therefore, that traders may have lost out from disposition effect trades is if Cash-Out resulted in lower liquidity (and higher trading costs). In our final analysis in Table 10, we examine whether this was the case. We regress four indicator variables -1) an indicator if there was a trade in that second, 2) trade size conditional on there being a trade, 3) the total trading volume measured at the bet-level, and 4) the quoted bid-ask (back-lay) spread. ${ }^{8}$ on our treatment (post Cash-Out) indicator. We find that trading frequency increased with Cash-Out, but average trade size declined. The net effect on total trading volume was not significant. Finally, the cost of trading - as measured by the bid-ask (back-lay) spread actually declined. In short, traders were no worse off after Cash-Out was introduced on this exchange, even though it appears to have increased the prevalence of disposition effect trades.

\footnotetext{
${ }^{8}$ The bid-ask spread is defined in implied win probability (percentage) terms. Therefore if the back bet is quoted at odds of 4 and the lay bet is quoted at odds of 5 , then the spread is equal to $(1 / 4-1 / 5) * 100=5 \%$.
} 


\section{Conclusion}

The disposition effect - the tendency of investors to sell stocks that have risen in value since purchase, and hold those that have not - is arguably one of the most prominent findings in behavioural finance. Part of this prominence can be ascribed to the robustness of the finding, as the effect has been observed amongst many different pools of brokerage account holders and laboratory subjects. The finding has also received attention because of the perception that the disposition effect is damaging to investors' trading performance, and may even have a distortionary impact on asset prices.

In this paper, we analyse the disposition effect in soccer betting markets. Midway through our sample, the betting exchange we study implemented a new design that increased the salience of a bettor's paper profits and losses. We ask whether an increase in this salience accentuated the disposition effect, by inducing bettors to sell off their winning bets, and hold their losing bets. Furthermore, we ask whether the disposition effect - and the selling pressure it creates for good performing assets - drags asset prices away from fundamental values (which we observe), either before or after the salience intervention.

We find that an increase in the salience of a bettor's paper profits and losses increased the disposition effect in this market. In particular, an increase in the salience of profits/losses led to more pronounced selling of extreme winning bets. In relation to the second question, however, we find no evidence that the disposition effect drags prices away from fundamentals, either before or after the increase in salience. In short, while there are market designs which can potentially reduce the magnitude of the disposition effect in financial markets, it is not clear that a market designer would choose to use them, or indeed that a regulator would choose to enforce their use.

\section{References}

- Ali, M., M., (1977). Probability and Utility Estimates for Racetrack Bettors. Journal of Political Economy, 85, 803-815.

- An, L., (2016). Asset Pricing when Traders Sell Extreme Winners and Losers. Review 
of Financial Studies, 29, 823-861.

- An, L., Argyle, B., (2015). V-Shaped Disposition: Mutual Fund Trading Behavior and Price Effects. Working paper.

- Barberis, N., Huang, M., (2008). Stocks as Lotteries: The Implications of Probability Weighting for Security Prices. American Economic Review, 98, 2066-2100.

- Barberis, N., Xiong, W., (2009). What Drives the Disposition Effect? An Analysis of a Long-Standing Preference-Based Explanation. Journal of Finance, 64, 751-784.

- Ben-David, I., Hirshleifer, D., (2012). Are Investors Really Reluctant to Realize their Losses? Trading Responses to Past Returns and the Disposition Effect. Review of Financial Studies, 25, 2485-2532.

- Birru, J., (2015). Confusion of Confusions: A Test of the Disposition Effect and Momentum. Review of Financial Studies, 28, 1849-1873.

- Brown, A., (2014). Information Processing Constraints and Asset Mispricing. Economic Journal, 124, 245-268.

- Brown, A., (2015). Information Acquisition in Ostensibly Efficient Markets. Economica, 82, 420-447.

- Brown, A., Yang, F., (2014). The Role of Speculative Trade in Market Efficiency: Evidence from a Betting Exchange. Review of Finance, forthcoming.

- Brown, A., Yang, F., (2016). Limited Cognition and Clustered Asset Prices: Evidence from Betting Markets. Journal of Financial Markets, 29, 27-46.

- Da Costa Jr. N., Goulart, M., Cupertino, C., Macedo Jr., J., Da Silva, S., (2013). The Disposition Effect and Investor Experience. Journal of Banking and Finance, 37, 1669-1675.

- De Bondt, W., F., M., Thaler (1985). Does the Stock Market Overreact? Journal of Finance, 40, 793-805. 
- DellaVigna, S., Pollet, J., M., (2009). Investor Inattention and Friday Earnings Announcements. Journal of Finance, 64, 709-749.

- Dhar, R., Zhu, N., (2006). Up Close and Personal: Investor Sophistication and the Disposition Effect. Management Science, 52, 726-740.

- Fama, E., F., (1998). Market Efficiency, Long-Term Returns, and Behavioral Finance. Journal of Financial Economics, 49, 283-306.

- Frazzini, A., (2006). The Disposition Effect and Underreaction to News. Journal of Finance, 61, 2017-2046.

- Frydman, C., Rangel, A., (2014). Debiasing the Disposition Effect by Reducing the Saliency of Information about a Stock's Purchase Price. Journal of Economic Behavior and Organization, 107, 542-552.

- Genesove, D., Mayer, C., (2001). Loss Aversion and Seller Behavior: Evidence from the Housing Market. Quarterly Journal of Economics, 116, 1233-1260.

- Grinblatt, M., Han, B., (2005). Prospect Theory, Mental Accounting, and Momentum. Journal of Financial Economics, 78, 311-339.

- Hartzmark, S., M., Solomon, D., H., (2012). Efficiency and the Disposition Effect in NFL Prediction Markets. Quarterly Journal of Finance, 2, 1250013.

- Hens, T., Vlcek, M., (2011) Does Prospect Theory Explain the Disposition Effect? Journal of Behavioral Finance, 12, 141-157

- Hirshleifer, D., Lim, S., S., Teoh, S., H., (2009). Driven to Distraction: Extraneous Events and Underreaction to Earnings News. Journal of Finance, 64, 2289-2325.

- Horrace, W., C., Oaxaca, R., L., (2006). Results on the Bias and Inconsistency of Ordinary Least Squares for the Linear Probability Model. Economics Letters, 90, 321327.

- Jegadeesh, N., Titman, S., (1993). Returns to Buying Winners and Selling Losers: Implications for Stock Market Efficiency. Journal of Finance, 48, 65-91. 
- Kahneman, D., Tversky, A., (1979). Prospect Theory: An Analysis of Decision under Risk. Econometrica, 47, 263-292.

- Kaustia, M., (2004). Market-Wide Impact of the Disposition Effect: Evidence from IPO Trading Volume. Journal of Financial Markets, 7, 207-235.

- Kumar, A., (2009). Who Gambles in the Stock Market? Journal of Finance, 66, 1889-1933.

- Kuo, W., Y., Lin, T., C., Zhao, J., (2015). Cognitive Limitation and Investment Performance: Evidence from Limit Order Clustering. Review of Financial Studies, 28, 838-875.

- Lee, C., M., C., Ready, M., J., (1991). Inferring Trade Direction from Intraday Data. Journal of Finance, 46, 733-746.

- List, J., A., (2003). Does Market Experience Eliminate Market Anomalies? Quaterly Journal of Economics, , 118, 41-71.

- Loomes, G., Starmer, C., Sugden, R., (2003). Do Anomalies Disappear in Repeated Markets? Economic Journal, 113, 153-166.

- Odean, T., (1998). Are Investors Reluctant to Realize their Losses? Journal of Finance, $53,1775-1798$.

- Shefrin, H., Statman, M., (1985). The Disposition to Sell Winners Too Early and Ride Losers Too Long: Theory and Evidence. Journal of Finance, 40, 777-790.

- Snowberg, E., Wolfers, J., (2010). Explaining the Favorite-Long Shot Bias: Is it Risk Love or Misperceptions? Journal of Political Economy, 118, 723-746.

- Tversky, A., Kahneman, D., (1992). Advances in Prospect Theory: Cumulative Representation of Uncertainty. Journal of Risk and Uncertainty, 5, 297-323.

- Weber, M., Camerer, C., F., (1998). The Disposition Effect in Securities Trading: An Experimental Analysis. Journal of Economic Behavior and Organization, 33, 167-184. 
- von Beschwitz, B., Massa, M., (2015). Biased Shorts: Short sellers' Disposition Effect and Limits to Arbitrage. International Finance Discussion Papers 1147. 


\section{Figures and Tables}

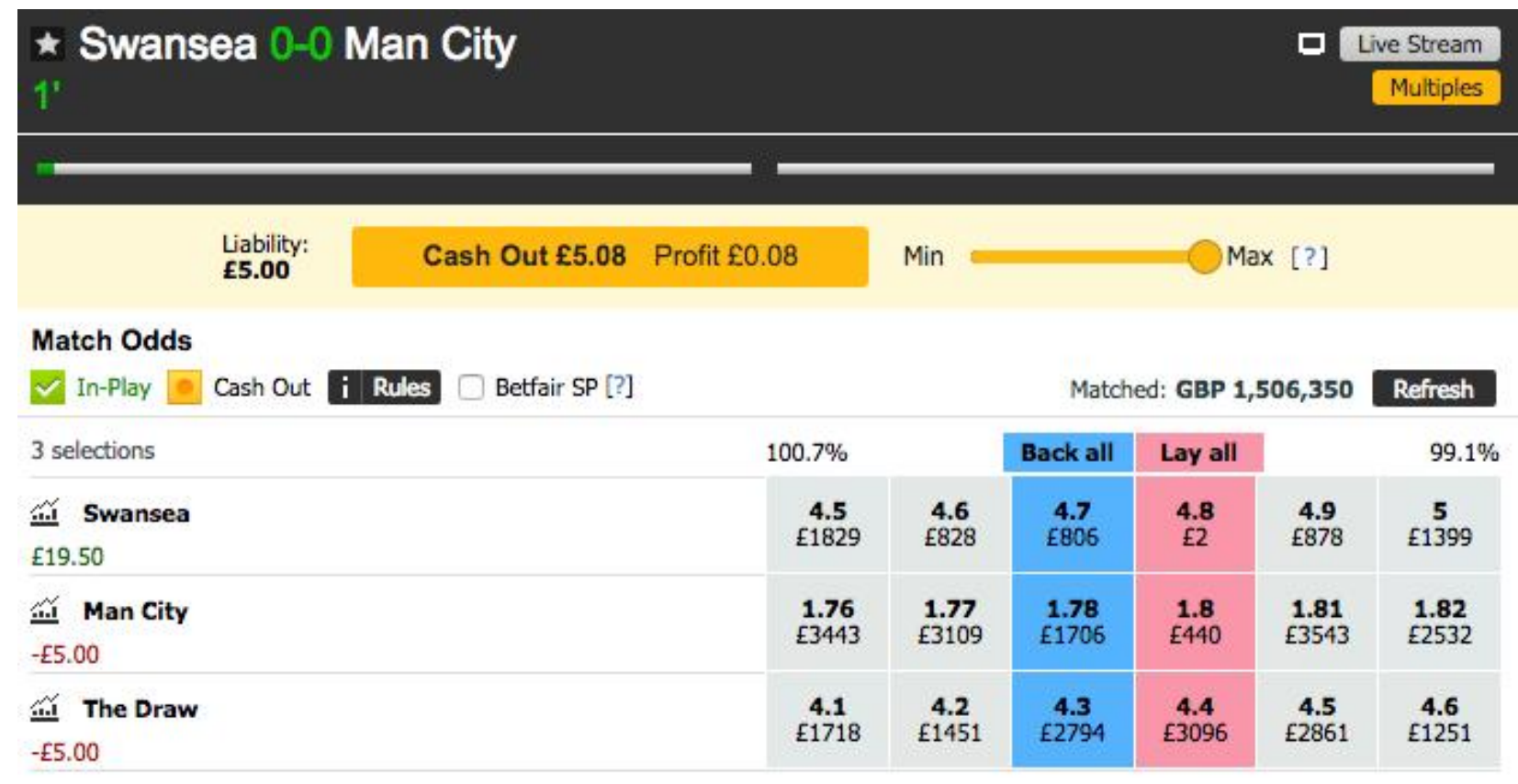

Figure 1: Salience and Cash-Outs. A screenshot of the Betfair limit order book. The Cash-Out feature in the middle of the screen was introduced in February 2011. Quotes to back (buy) an outcome are on the left, with quotes to lay (sell) an outcome on the right. The screenshot is taken from inplay betting on the match between Swansea City and Manchester City on the 17th May 2015, a match outside of our sample. 


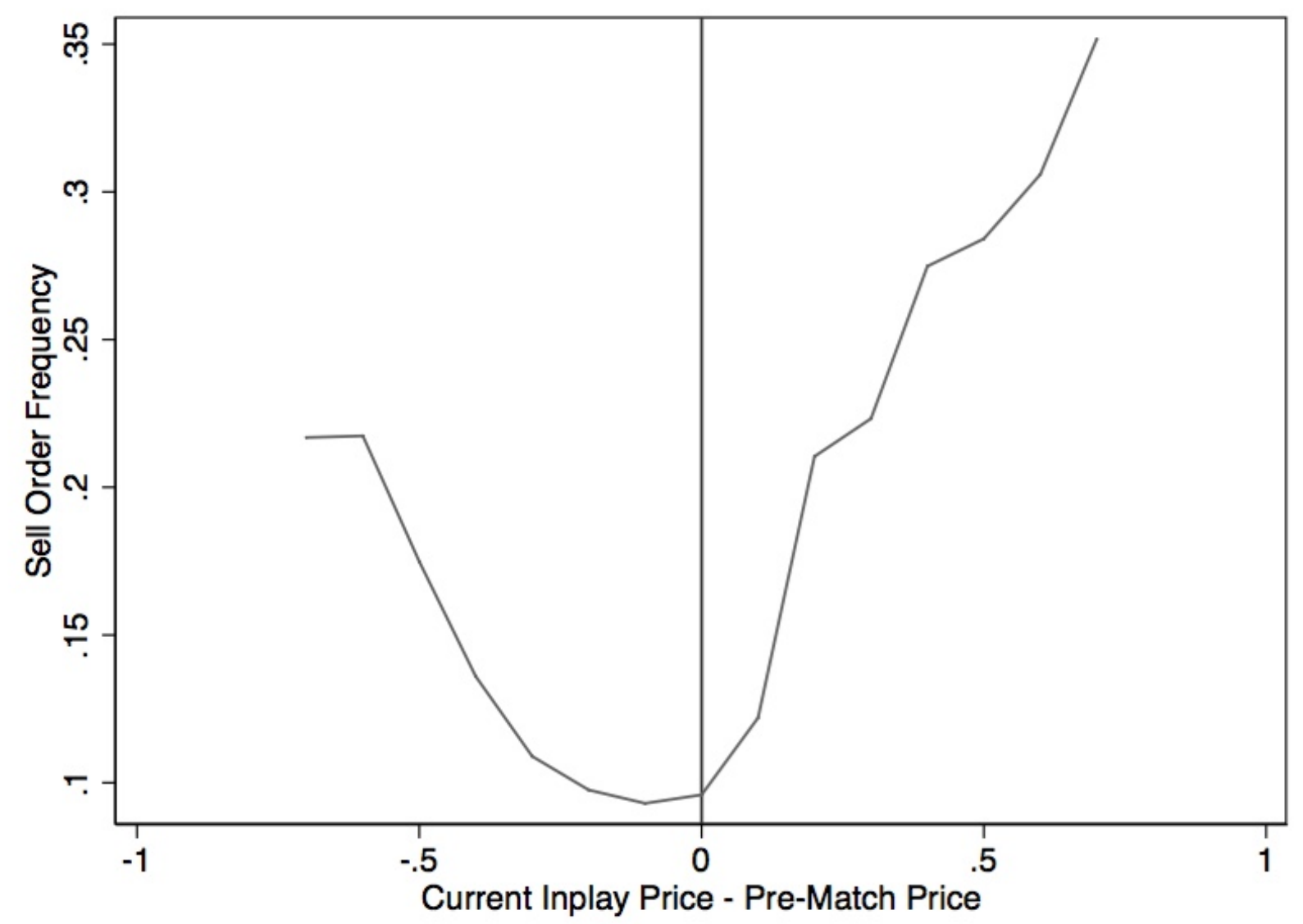

Figure 2: Sell Orders. The frequency of sell (lay) market orders, plotted against the difference between the current inplay price (implied win probability) and the average prematch price for that bet. This difference is rounded to 1 decimal place to create sufficiently large buckets of observations. Data are taken from Betfair exchange betting on English Premier League soccer matches from season 2008/9 to 2013/14. 


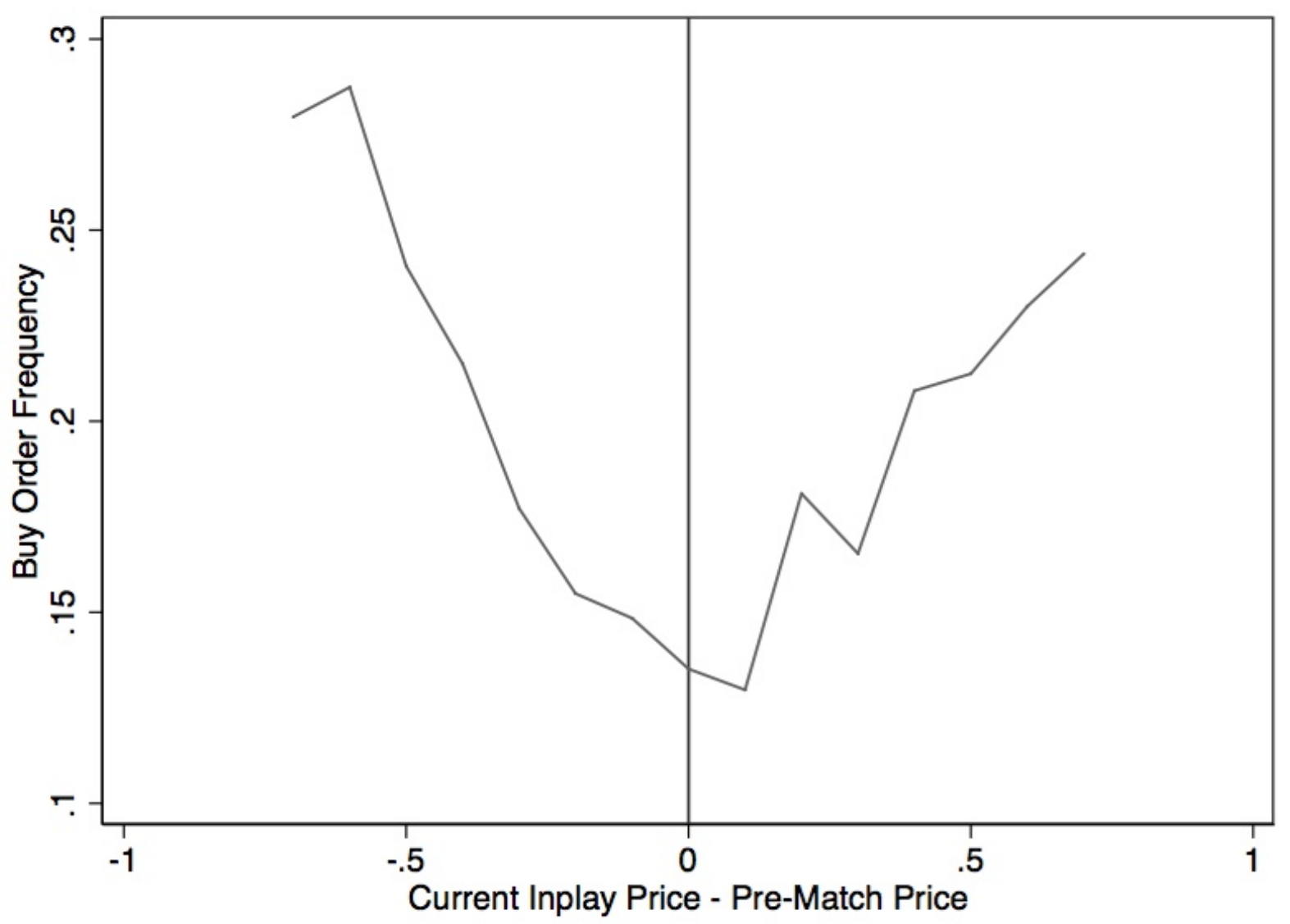

Figure 3: Buy Orders. The frequency of buy (back) market orders, plotted against the difference between the current inplay price (implied win probability) and the average prematch price for that bet. This difference is rounded to 1 decimal place to create sufficiently large buckets of observations. Data are taken from Betfair exchange betting on English Premier League soccer matches from season 2008/9 to 2013/14. 


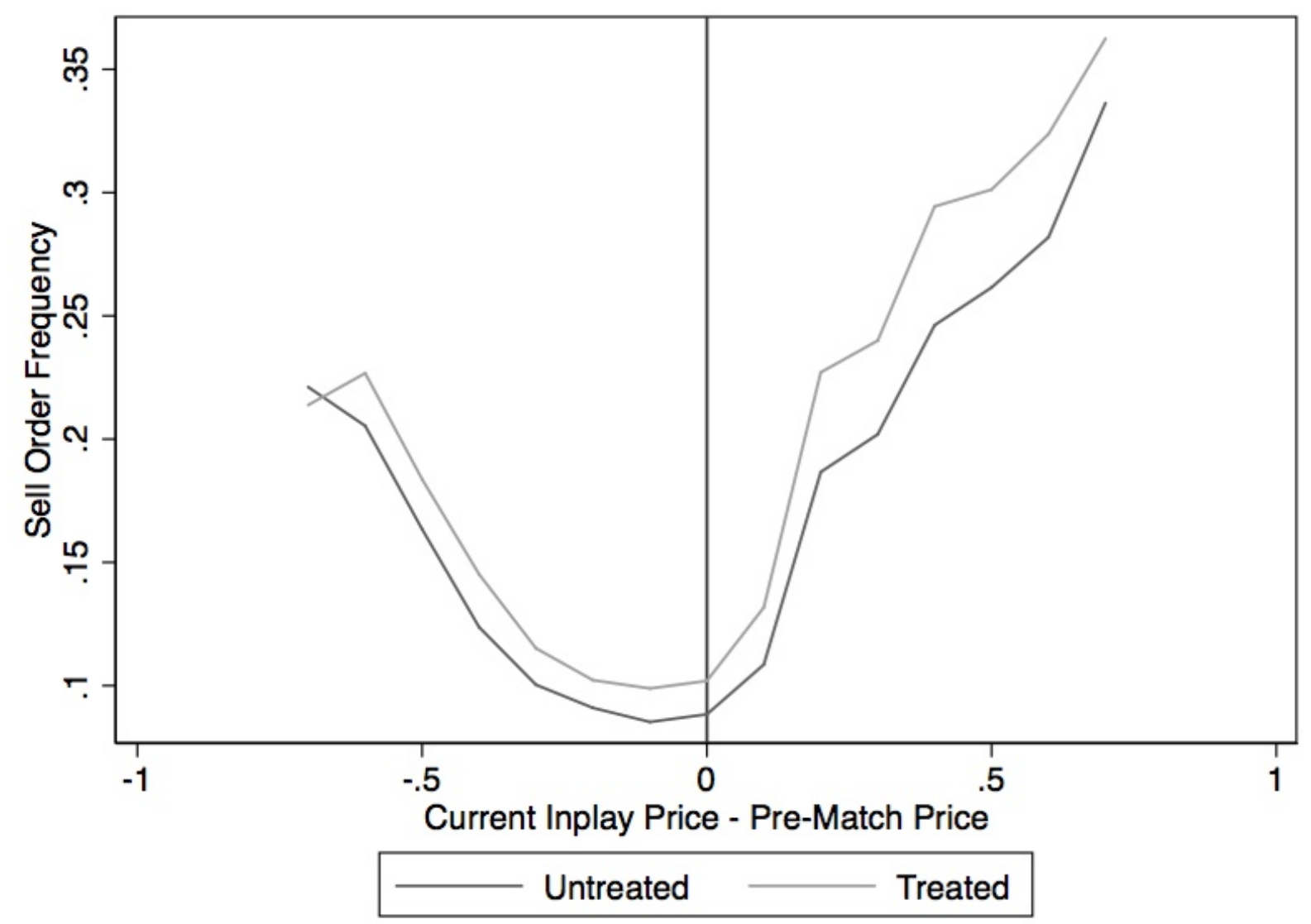

Figure 4: Sell Orders: Salience Treatment. The frequency of sell (lay) market orders, plotted against the difference between the current inplay price (implied win probability) and the average pre-match price for that bet. This difference is rounded to 1 decimal place to create sufficiently large buckets of observations. The sample is broken down into the period prior to Cash-Out ('Untreated'), and the period after the introduction of Cash-Out in February 2011 ('Treated'). Data are taken from Betfair exchange betting on English Premier League soccer matches from season 2008/9 to 2013/14. 


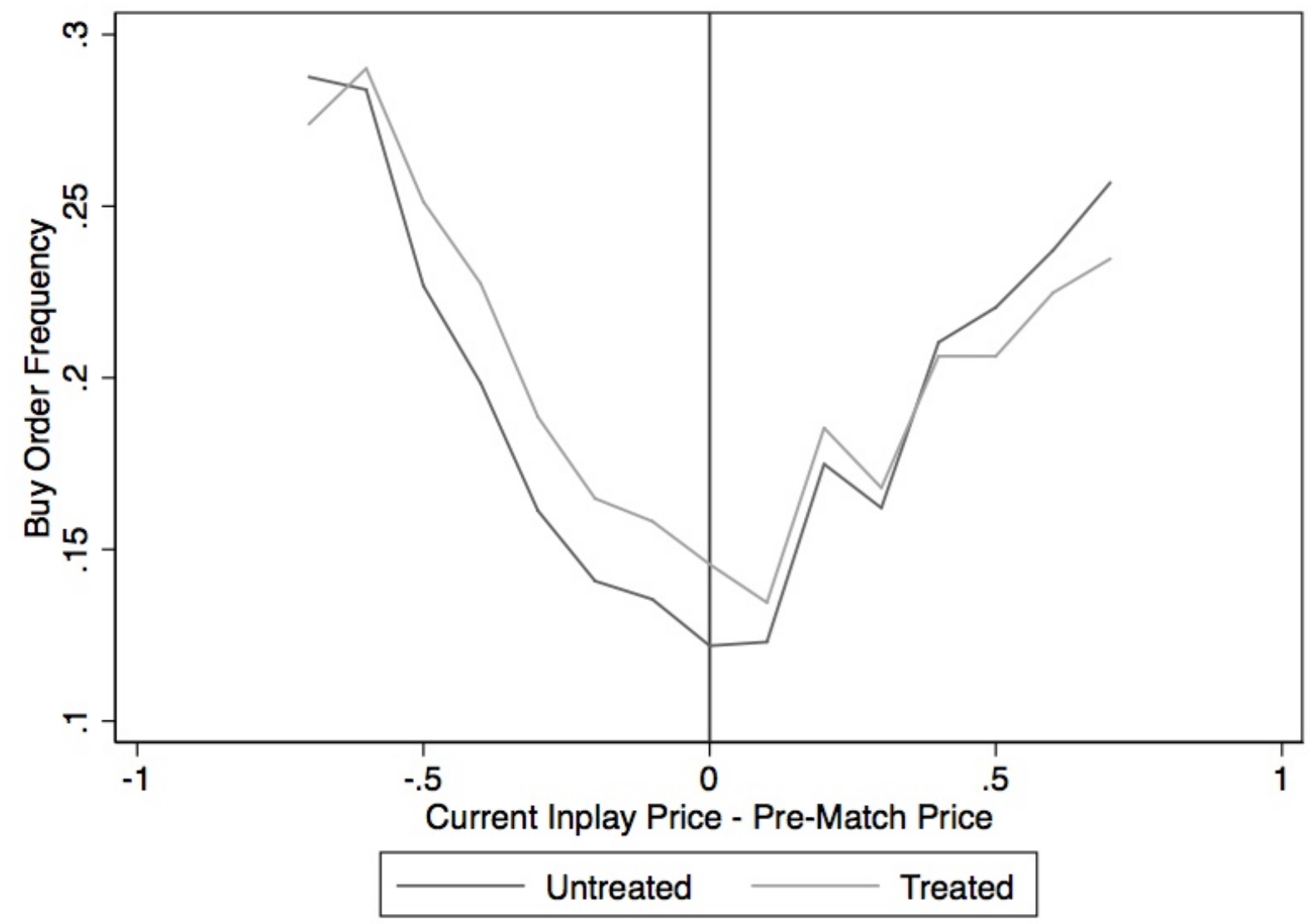

Figure 5: Buy Orders: Salience Treatment. The frequency of buy (back) market orders, plotted against the difference between the current inplay price (implied win probability) and the average pre-match price for that bet. This difference is rounded to 1 decimal place to create sufficiently large buckets of observations. The sample is broken down into the period prior to Cash-Out ('Untreated'), and the period after the introduction of Cash-Out in February 2011 ('Treated'). Data are taken from Betfair exchange betting on English Premier League soccer matches from season 2008/9 to 2013/14. 


\begin{tabular}{c|ccccc}
\hline Table 1: Summary Statistics & \multicolumn{7}{c}{} \\
\hline Prices (Implied Win Probability) & Obs & Mean & Std. Dev. & Min & Max \\
\hline Pre-Match Price & $89,087,137$ & .333 & .18 & .024 & .921 \\
Inplay Price & $39,647,847$ & .332 & .266 & .001 & .985 \\
\hline Orders & Obs & Mean & Std. Dev. & Min & Max \\
\hline Inplay Back (Buy) Order & $42,358,869$ & .145 & .352 & 0 & 1 \\
Inplay Lay (Sell) Order & $42,358,869$ & .122 & .328 & 0 & 1 \\
\hline
\end{tabular}

Summary statistics on prices (implied win probabilities) and orders. In the top panel, summary statistics on prices are displayed for both the pre-match period and the inplay period. Prices are sampled every second. In the bottom panel, summary statistics are displayed on two indicator variables: one for back (buy) market orders and one for lay (sell) market orders. The direction of trade (buy or sell) is classified by the Lee and Ready (1991) algorithm (see Section 2). 


\begin{tabular}{c|c|c|c}
\hline Table 2: Disposition Effect & \multicolumn{3}{|c}{} \\
\hline Dependent Variable: & Lay (Sell) Order & Dependent Variable: & Back (Buy) Order \\
\hline Intercept & $0.099^{* * * *}$ & Intercept & $0.154^{* * * *}$ \\
& $(.000)$ & & $(.001)$ \\
Above Pre-Match Price & $0.07^{* * * *}$ & Below Pre-Match Price & 0.000 \\
& $(.001)$ & & $(.001)$ \\
No. of Clusters (Bets) & 6,318 & No. of Clusters (Bets) & 6,318 \\
No. of Observations & $39,623,646$ & No. of Observations & $39,623,646$ \\
$R^{2}$ & 0.0109 & $R^{2}$ & 0 \\
\hline
\end{tabular}

Regressions to establish whether traders exhibit a disposition effect in this market. In the left panel, an indicator variable equalling 1 if a lay (sell) market order was placed, is regressed on an indicator variable equalling 1 if the bet was, at the time, quoted at a higher price (implied win probability) than its pre-match average. In the right panel, an indicator variable equalling 1 if a back (buy) market order was placed, is regressed on an indicator variable equalling 1 if the bet was, at the time, quoted at a lower price (implied win probability) than its pre-match average. The second regression looks for a reverse or short-sellers' disposition effect. Data are taken from Betfair exchange betting on matches from the 2008/9 season to the $2013 / 14$ season of the English Premier League. Estimation is by OLS, heteroskedasticity-consistent standard errors are clustered at the bet level, and $* * * *$ indicates significance at the $0.1 \%$ level. 


\begin{tabular}{|c|c|}
\hline Table 3: V-Shaped Disposition Effect & \\
\hline Dependent Variable: & Lay (Sell) Order \\
\hline \multirow[t]{2}{*}{ Intercept } & $0.084^{* * * *}$ \\
\hline & $(.001)$ \\
\hline \multirow[t]{2}{*}{ Above Pre-Match Price } & $0.012^{* * * *}$ \\
\hline & $(.001)$ \\
\hline \multirow[t]{2}{*}{ Abs. Diff. in Price } & $0.115^{* * * *}$ \\
\hline & $(.006)$ \\
\hline \multirow[t]{2}{*}{ Above Pre-Match Price*Abs. Diff. in Price } & $0.291^{* * * *}$ \\
\hline & $(.01)$ \\
\hline No. of Clusters (Bets) & 6,318 \\
\hline No. of Observations & $39,647,300$ \\
\hline$R^{2}$ & 0.031 \\
\hline Dependent Variable: & Back (Buy) Order \\
\hline \multirow[t]{2}{*}{ Intercept } & $0.12^{* * * *}$ \\
\hline & $(.001)$ \\
\hline \multirow[t]{2}{*}{ Below Pre-Match Price } & $0.013^{* * * *}$ \\
\hline & $(.001)$ \\
\hline \multirow[t]{2}{*}{ Abs. Diff. in Price } & $0.19^{* * * *}$ \\
\hline & $(.005)$ \\
\hline \multirow[t]{2}{*}{ Below Pre-Match Price*Abs. Diff. in Price } & $-0.021^{*}$ \\
\hline & $(.012)$ \\
\hline No. of Clusters (Bets) & 6,318 \\
\hline No. of Observations & $39,647,300$ \\
\hline$R^{2}$ & 0.005 \\
\hline
\end{tabular}

Regressions to establish whether traders exhibit a V-shaped disposition effect in this market. In the top panel we analyse sell orders (the standard disposition effect), with buy orders (the short-sellers' disposition effect) in the bottom panel. In the top panel, an indicator variable equalling 1 if a lay (sell) market order was placed, is regressed on an indicator variable equalling 1 if the bet was, at the time, quoted at a higher price (implied win probability) than its pre-match average, the absolute difference between the pre-match price and the current price, and an interaction between the two variables. We repeat the same exercise in the bottom panel for short-sellers; for these traders profits are reaped when the bet is priced lower than it was pre-match. Data are taken from Betfair exchange betting on matches from the 2008/9 season to the 2013/14 season of the English Premier League. Estimation is by OLS, heteroskedasticity-consistent standard errors are clustered at the bet level, and ${ }^{* * * *}$ and $*$ indicates significance at the $0.1 \%$ and $10 \%$ level respectively. 


\begin{tabular}{c|c|c|c}
\hline Table 4: Salience Treatment & \multicolumn{2}{|c}{} \\
\hline Dependent Variable: & Lay (Sell) Order & Dependent Variable: & Back (Buy) Order \\
\hline Intercept & $0.091^{* * * *}$ & Intercept & $0.148^{* * * *}$ \\
& $(.001)$ & $.001)$ & $-0.007^{* * * *}$ \\
Above Pre-Match Price & $0.062^{* * * *}$ & Below Pre-Match Price & $(.002)$ \\
Treatment & $(.002)$ & Treatment & $0.01^{* * * *}$ \\
& $0.014^{* * * *}$ & & $(.002)$ \\
Above Pre-Match Price*Treatment & $(.001)$ & Below Pre-Match Price*Treatment & $0.014^{* * * *}$ \\
& $\left(.014^{* * * *}\right.$ & & $(.003)$ \\
No. of Clusters (Bets) & 6,318 & No. of Clusters (Bets) & 6,318 \\
No. of Observations & $39,623,646$ & No. of Observations & $39,623,646$ \\
$R^{2}$ & 0.0118 & $R^{2}$ & 0.0008 \\
\hline
\end{tabular}

Regressions to establish whether an increase in the salience of a trader's position - brought about by the introduction of the Cash-Out facility on Betfair in February 2011 - exacerbates the disposition effect. In the left panel, an indicator variable equalling 1 if a lay (sell) market order was placed, is regressed on an indicator variable equalling 1 if the bet was, at the time, quoted at a higher price (implied win probability) than its pre-match average, an indicator variable equalling 1 if the match was post-treatment (i.e. after February 2011), and an interaction between the two aforementioned indicators. In the right panel, an indicator variable equalling 1 if a back (buy) market order was placed, is regressed on an indicator variable equalling 1 if the bet was, at the time, quoted at a lower price (implied win probability) than its pre-match average, an indicator variable equalling 1 if the match was post-treatment (i.e. after February 2011), and an interaction between the two aforementioned indicators. The second regression looks for a reverse or short-sellers' disposition effect, and any impact of the Cash-Out facility on this effect. Data are taken from Betfair exchange betting on matches from the 2008/9 season to the 2013/14 season of the English Premier League. Estimation is by OLS, heteroskedasticity-consistent standard errors are clustered at the bet level, and $* * * *$ and $* * *$ indicates significance at the $0.1 \%$ and $1 \%$ level respectively. 


\begin{tabular}{c|c|c|c}
\hline Table 5: Salience (Robustness) & \multicolumn{2}{|c}{} \\
\hline Dependent Variable: & Lay (Sell) Order & Dependent Variable: & Back (Buy) Order \\
\hline Intercept & $0.09^{* * * *}$ & Intercept & $0.146^{* * * *}$ \\
& $(.001)$ & Below Pre-Match Price & $-0.01^{* * * *}$ \\
Above Pre-Match Price & $0.059^{* * * *}$ & & $(.002)$ \\
Treatment & $(.002)$ & Treatment & $0.014^{* * * *}$ \\
& $0.017^{* * * *}$ & & $(.002)$ \\
Above Pre-Match Price*Treatment & $(.002)$ & Below Pre-Match Price*Treatment & $0.018^{* * * *}$ \\
& $0.017^{* * * *}$ & & $(.003)$ \\
No. of Clusters (Bets) & $(.003)$ & No. of Clusters (Bets) & 5,254 \\
No. of Observations & 5,254 & No. of Observations & $32,884,742$ \\
$R^{2}$ & $32,884,742$ & $R^{2}$ & 0.0013 \\
\hline
\end{tabular}

Regressions to establish whether an increase in the salience of a trader's position - brought about by the introduction of the Cash-Out facility on Betfair in February 2011 - exacerbates the disposition effect. This time, data from the 2010/11 season is dropped from the analysis to ensure we have complete seasons before and after the introduction of Cash-Out. In the left panel, an indicator variable equalling 1 if a lay (sell) market order was placed, is regressed on an indicator variable equalling 1 if the bet was, at the time, quoted at a higher price (implied win probability) than its pre-match average, an indicator variable equalling 1 if the match was post-treatment (i.e. after February 2011), and an interaction between the two aforementioned indicators. In the right panel, an indicator variable equalling 1 if a back (buy) market order was placed, is regressed on an indicator variable equalling 1 if the bet was, at the time, quoted at a lower price (implied win probability) than its pre-match average, an indicator variable equalling 1 if the match was post-treatment (i.e. after February 2011), and an interaction between the two aforementioned indicators. The second regression looks for a reverse or short-sellers' disposition effect, and any impact of the Cash-Out facility on this effect. Data are taken from Betfair exchange betting on matches from the 2008/9 season to the 2013/14 season of the English Premier League (excluding season 2010/11). Estimation is by OLS, heteroskedasticity-consistent standard errors are clustered at the bet level, and $* * * *$ indicates significance at the $0.1 \%$ level. 


\begin{tabular}{c|c|c|c}
\hline Table 6: Placebo Tests & \multicolumn{2}{|c}{} \\
\hline Dependent Variable: & Lay (Sell) Order & Dependent Variable: & Back (Buy) Order \\
\hline Intercept & $0.085^{* * * *}$ & Intercept & $0.138^{* * * *}$ \\
& $(.002)$ & & $(.002)$ \\
Above Pre-Match Price & $0.056^{* * * *}$ & Below Pre-Match Price & $-0.013^{* * * *}$ \\
& $(.003)$ & & $(.003)$ \\
Placebo & $0.009^{* * *}$ & Placebo & $0.015^{* * * *}$ \\
& $(.002)$ & & $(.003)$ \\
Above Pre-Match Price*Placebo & 0.005 & Below Pre-Match Price*Placebo & 0.006 \\
No. of Clusters (Bets) & $(.004)$ & & $(.005)$ \\
No. of Observations & 2,037 & No. of Clusters (Bets) & 2,037 \\
$R^{2}$ & $12,883,311$ & No. of Observations & $12,883,311$ \\
\hline
\end{tabular}

Placebo tests to establish whether the earlier results were indeed due to the introduction of the Cash-Out facility, or due to time trends in the frequency of buy and sell orders. This time, only data from the 2008/9 and 2009/10 seasons are included, both prior to the introduction of Cash-Out. In the left panel, an indicator variable equalling 1 if a lay (sell) market order was placed, is regressed on an indicator variable equalling 1 if the bet was, at the time, quoted at a higher price (implied win probability) than its pre-match average, an indicator variable equalling 1 if the match was after the placebo (i.e. in season 2009/10), and an interaction between the two aforementioned indicators. In the right panel, an indicator variable equalling 1 if a back (buy) market order was placed, is regressed on an indicator variable equalling 1 if the bet was, at the time, quoted at a lower price (implied win probability) than its pre-match average, an indicator variable equalling 1 if the match was after the placebo (i.e. in season 2009/10), and an interaction between the two aforementioned indicators. Estimation is by OLS, heteroskedasticity-consistent standard errors are clustered at the bet level, and $* * * *$ and $* * *$ indicates significance at the $0.1 \%$ and $1 \%$ level respectively. 


\begin{tabular}{|c|c|}
\hline Dependent Variable: & Lay (Sell) Order \\
\hline \multirow[t]{2}{*}{ Intercept } & $0.077^{* * * *}$ \\
\hline & $(.001)$ \\
\hline \multirow[t]{2}{*}{ Above Pre-Match Price } & $0.01 * * * *$ \\
\hline & $(.001)$ \\
\hline \multirow[t]{2}{*}{ Treatment } & $0.012^{* * * *}$ \\
\hline & $(.001)$ \\
\hline \multirow[t]{2}{*}{ Abs. Diff. in Price } & $0.109^{* * * *}$ \\
\hline & $(.009)$ \\
\hline \multirow[t]{2}{*}{ Above Pre-Match Price*Treatment } & 0.003 \\
\hline & $(.002)$ \\
\hline \multirow[t]{2}{*}{ Above Pre-Match Price*Abs. Diff. in Price } & $0.261 * * * *$ \\
\hline & $(.015)$ \\
\hline \multirow[t]{2}{*}{ Treatment*Abs. Diff. in Price } & 0.008 \\
\hline & $(.012)$ \\
\hline \multirow[t]{2}{*}{ Above Pre-Match Price*Treatment*Abs. Diff in Price } & $0.054^{* * *}$ \\
\hline & $(.02)$ \\
\hline No. of Clusters (Bets) & 6,318 \\
\hline No. of Observations & $39,647,300$ \\
\hline$R^{2}$ & 0.032 \\
\hline Dependent Variable: & Back (Buy) Order \\
\hline \multirow[t]{2}{*}{ Intercept } & $0.109^{* * * *}$ \\
\hline & $(.001)$ \\
\hline \multirow[t]{2}{*}{ Below Pre-Match Price } & $0.01 * * * *$ \\
\hline & $(.002)$ \\
\hline \multirow[t]{2}{*}{ Treatment } & $0.019 * * * *$ \\
\hline & $(.002)$ \\
\hline \multirow[t]{2}{*}{ Abs. Diff. in Price } & $0.221^{* * * *}$ \\
\hline & $(.008)$ \\
\hline \multirow[t]{2}{*}{ Below Pre-Match Price*Treatment } & 0.004 \\
\hline & $(.003)$ \\
\hline \multirow[t]{2}{*}{ Below Pre-Match Price*Abs. Diff. in Price } & $-0.053^{* * *}$ \\
\hline & $(.018)$ \\
\hline \multirow[t]{2}{*}{ Treatment*Abs. Diff. in Price } & $-0.054^{* * * *}$ \\
\hline & $(.01)$ \\
\hline \multirow[t]{2}{*}{ Below Pre-Match Price*Treatment*Abs. Diff in Price } & $0.055^{* *}$ \\
\hline & $(.024)$ \\
\hline No. of Clusters (Bets) & 6,318 \\
\hline No. of Observations & $39,647,300$ \\
\hline$R^{2}$ & 0.006 \\
\hline
\end{tabular}

Regressions to establish whether an increase in the salience of a trader's position - brought about by the introduction of the Cash-Out facility on Betfair in February 2011 - exacerbated the V-shaped disposition effect. In the top panel we analyse sell orders (the standard disposition effect), with buy orders (the short-sellers' disposition effect) in the bottom panel. In the top panel, an indicator variable equalling 1 if a lay (sell) market order was placed, is regressed on an indicator variable equalling 
1 if the bet was, at the time, quoted at a higher price (implied win probability) than its pre-match average, an indicator variable equalling 1 if Cash-Out had been introduced, the absolute difference between the pre-match price and the current price, and interactions between these three variables. We repeat the same exercise in the bottom panel for short-sellers; for these traders profits are reaped when the bet is priced lower than it was pre-match. Data are taken from Betfair exchange betting on matches from the 2008/9 season to the 2013/14 season of the English Premier League. Estimation is by OLS, heteroskedasticityconsistent standard errors are clustered at the bet level, and $* * * *, * * *$ and $* *$ indicates significance at the $0.1 \%, 1 \%$ and $5 \%$ level respectively. 


\begin{tabular}{c|cc}
\hline Table 8: Disposition Effect and Prices & & \\
\hline Dependent Variable: & Win Indicator & Win Indicator \\
\hline Intercept & 0.004 & 0.003 \\
Price & $(.005)$ & $(.007)$ \\
& $0.989^{* * * *}$ & $0.989^{* * * *}$ \\
Above Pre-Match Price & $(.016)$ & $(.016)$ \\
& 0.008 & 0.007 \\
Treatment & $(.009)$ & $(.012)$ \\
& & 0.001 \\
Above Pre-Match Price*Treatment & & $(.009)$ \\
& & 0.001 \\
No. of Clusters (Bets) & 6,318 & $(.013)$ \\
No. of Observations & $39,647,300$ & $39,647,300$ \\
$R^{2}$ & 0.3164 & 0.3164 \\
\hline
\end{tabular}

Regressions to establish whether the disposition effect has an impact on asset prices. If it does, bets will win more often - after controlling for their price (implied win probability) - if quoted at prices higher than their pre-match price, as punters with the disposition effect are induced to cash-out too cheaply. In the first regression, an indicator variable equalling 1 if the bet won, is regressed on the inplay quoted price (implied win probability), an indicator variable equalling 1 if the bet was, at the time, quoted at a higher price than its prematch average. In the second regression, an indicator for the post-treatment period (after the introduction of Cash-Out in February 2011) is included, along with an interaction between the last two indicator variables. The second regression analyses whether the increased salience provided by the Cash-Out facility has any impact on asset prices. Data are taken from Betfair exchange betting on matches from the 2008/9 season to the 2013/14 season of the English Premier League. Estimation is by OLS, heteroskedasticity-consistent standard errors are clustered at the bet level, and **** indicates significance at the $0.1 \%$ level. 


\begin{tabular}{|c|c|c|}
\hline \multicolumn{3}{|l|}{ Table 9: V-Shaped Disposition Effect and Prices } \\
\hline Dependent Variable: & Win Indicator & Win Indicator \\
\hline \multirow[t]{2}{*}{ Intercept } & -0.002 & 0.000 \\
\hline & $(.008)$ & $(.011)$ \\
\hline \multirow[t]{2}{*}{ Price } & $0.995^{* * * *}$ & $0.995^{* * * *}$ \\
\hline & $(.025)$ & $(.025)$ \\
\hline \multirow[t]{2}{*}{ Above Pre-Match Price } & 0.013 & 0.001 \\
\hline & $(.008)$ & $(.012)$ \\
\hline \multirow[t]{2}{*}{ Abs. Diff. in Price } & 0.048 & 0.026 \\
\hline & $(.034)$ & $(.048)$ \\
\hline \multirow[t]{2}{*}{ Above Pre-Match Price*Abs. Diff. in Price } & -0.049 & 0.013 \\
\hline & $(.059)$ & $(.072)$ \\
\hline \multirow[t]{2}{*}{ Treatment } & & -0.004 \\
\hline & & $(.013)$ \\
\hline \multirow[t]{2}{*}{ Above Pre-Match Price* Treatment } & & 0.02 \\
\hline & & $(.016)$ \\
\hline \multirow[t]{2}{*}{ Treatment*Abs. Diff. in Price } & & 0.03 \\
\hline & & $(.058)$ \\
\hline \multirow[t]{2}{*}{ Above Pre-Match Price*Treatment*Abs. Diff in Price } & & -0.112 \\
\hline & & $(.071)$ \\
\hline No. of Clusters (Bets) & 6,318 & 6,318 \\
\hline No. of Observations & $39,647,300$ & $39,647,300$ \\
\hline$R^{2}$ & 0.316 & 0.316 \\
\hline
\end{tabular}

Regressions to establish whether the V-shaped disposition effect has an impact on asset prices. If it does, bets will win more often - after controlling for their price (implied win probability) - if quoted prices are very different from the pre-match price, particularly if the price is above the pre-match price. In the first regression, an indicator variable equalling 1 if the bet won, is regressed on the inplay quoted price (implied win probability), an indicator variable equalling 1 if the bet was, at the time, quoted at a higher price than its pre-match average, the absolute difference between the current and pre-match price, and an interaction between these two variables. In the second regression, an indicator for the post-treatment period (after the introduction of Cash-Out in February 2011) is added, along with an interaction between the three variables. The second regression analyses whether the increased salience provided by the Cash-Out facility has any impact on asset prices, via the V-shaped disposition effect. Data are taken from Betfair exchange betting on matches from the 2008/9 season to the 2013/14 season of the English Premier League. Estimation is by OLS, heteroskedasticity-consistent standard errors are clustered at the bet level, and **** indicates significance at the $0.1 \%$ level. 


\begin{tabular}{c|cc}
\hline Table 10: Salience and Market Liquidity & & \\
\hline Dependent Variable: & Trade Indicator & Trade Size \\
\hline Intercept & $0.252^{* * * *}$ & $0.403^{* * * * *}$ \\
Treatment & $(.002)$ & $(.008)$ \\
& $0.039^{* * * *}$ & $-0.04^{* * * *}$ \\
No. of Clusters (Bets) & $(.004)$ & $(.011)$ \\
No. of Observations & 6,318 & 6,318 \\
$R^{2}$ & $42,324,835$ & $11,641,678$ \\
Dependent Variable: & 0.001 & 0.000 \\
\hline Intercept & Total Volume & Quoted Spread \\
\hline Treatment & $691.4^{* * * *}$ & $0.947^{* * * *}$ \\
& $(20.1)$ & $(.011)$ \\
No. of Clusters (Bets) & 11.79 & $-0.055^{* * * *}$ \\
No. of Observations & $(27.8)$ & $(.015)$ \\
$R^{2}$ & NA & 6,318 \\
\hline
\end{tabular}

Regressions to establish whether the introduction of Cash-Out had any effect on market liquidity. We use four dependent variables: 1) an indicator if there was a trade in that second, 2) trade size conditional on there being a trade, 3) the total trading volume measured at the bet-level, and 4) the quoted bid-ask (back-lay) spread. These four variables are separately regressed on a treatment indicator variable, equalling 1 if CashOut had been introduced at the time. Data are taken from Betfair exchange betting on matches from the 2008/9 season to the 2013/14 season of the English Premier League. Estimation is by OLS, heteroskedasticityconsistent standard errors are clustered at the bet level (where applicable), and $* * * *$ indicates significance at the $0.1 \%$ level. 